\title{
Regional Heterogeneity of Malaria Prevalence And Associated Risk Factors Among Children Under Five In Togo: Evidence From National Malaria Indicators Survey
}

Gountante Kombate ( $\square$ gountanto@gmail.com )

Society for Study and Research in Public Health https://orcid.org/0000-0003-0014-5528

Wakpaouyare Gmakouba

Ministry of Health, public hygiene and universal access to care

Susana Scott

London School of Hygiene \& Tropical Medicine

Komi Ameko Azianu

Ministry of Health, public hygiene and universal access to care

Didier Koumavi Ekouevi

University of Lomé

Marianne A.B. van der Sande

Institute of Tropical Medicine

\section{Research Article}

Keywords: Regional heterogeneity, Malaria prevalence, Children under 5 years, To

Posted Date: December 13th, 2021

DOI: https://doi.org/10.21203/rs.3.rs-1096405/v1

License: (c) (i) This work is licensed under a Creative Commons Attribution 4.0 International License.

Read Full License 


\section{Abstract}

Background: Malaria remains one of the main causes of morbidity and death among children less than 5 . In Togo, despite intensification of malaria control interventions, persistence in malaria prevalence was observed and appears to vary from one region to another within the country. The aim of this study is to explore further regional heterogeneities in malaria prevalence and to determine associated risk factors.

Methods: Data from the cross-sectional survey of the nationally representative 2017 Togo malaria indicator survey was used. Children aged 6-59 months in the selected households were tested for malaria using the rapid diagnostic test (RDT) and the microscopy. Univariate and multivariate logistic regression analysis were preformed using Generalized Linear Models.

Results: A total of 3271 children under five (2441 in rural areas and 830 in urban areas was enrolled. Overall $26 \%$ of children tested positive for malaria, as confirmed by microscopy, ranging from $5.3 \%$ in the Lomé Commune region to $43.6 \%$ in the Plateaux region. In multivariate analysis, factors associated with malaria prevalence were living in the Plateaux region ( $\mathrm{aOR}=4.24,95 \% \mathrm{Cl}[2.38-7.65])$, and the Maritime region (aOR=2.02, 95\% $\mathrm{Cl}$ [1.13-3.66], compared to Lomé Commune region); age 24 to 35 months $(\mathrm{aOR}=1.46,95 \% \mathrm{Cl}[1.13-1.88)$ and age 36 to 59 months (aOR=2.5, 95\% Cl [2.04-3.09]) ], Compared to those age 6-23 months; households within the richest wealth quintile (a.OR $=0.22,95 \% \mathrm{Cl}[0.11-0.41]$, compared to poorest) and residence in rural areas $(\mathrm{aOR}=2.02,95 \% \mathrm{Cl}$ [1.32-3.13], compared to resident in urban).

Conclusion: Interventions that targeted use of combined prevention measures, adapted to older children living in rural areas and particularly in the regions of high malaria prevalence, could result in better malaria control in Togo.

\section{Background}

Malaria continues to be major public health problem. In 2020, a total of 229 million cases of malaria and 409,000 deaths were reported, with the vast majority occurring in sub-Saharan African ( $94 \%$ of malaria cases and $99 \%$ of deaths)(1). The under five year old continue to be at greatest risk of severe malaria, accounting for $67 \%$ of all malaria deaths. The magnitude of the problem in this region of the world is influenced by a number of environment-related factors, vector-related factors, and human-related factors (2).

In Togo, malaria is endemic with a high prevalence of infection. In 2018, 2,002,877 cases and 905 deaths were recorded on the general population of 7265286 inhabitants (3). During the same period, children under five years of age represented $31.6 \%$ of cases. This prevalence shows the extent of this disease in this age group but hides a strong heterogeneity within the regions ranging from $2.6 \%$ in the common Lomé Commune region to $43.0 \%$ in the Savannah region (3). The socio-economic burden on the population is significant. In one study the average expenditure per household on malaria prevention measures was $\$ 8$, which represents $5-15 \%$ of monthly household income(4). Through the Global Technical Strategy for Malaria Control (2016-2030), Togo is one of the 35 countries committed to 
eliminate malaria by 2030 (5). Based on this recommendation, the Togolese government through the National Malaria Control Program (PNPL) has developed five-year plans, the first of which (National Health Development Plan 2017-2022) builds on known high-impact interventions to control malaria in the country with the goal to move towards malaria elimination by 2030 (6). The major strategies adopted in this plan are universal coverage of long-lasting insecticidal nets (LLINs), seasonal malaria chemoprevention (SMC), mass treatment, community case management by community health workers (CHW) and indoor residual spraying (IRS)(6).

Despite these initiatives, malaria remains a challenge in the country. A retrospective longitudinal study using PNLP routine data from 2008 - 2017, showed an average annual increase in malaria cases in children under five of $+13.1 \%$, also with strong heterogeneity ranging from $+6.3 \%$ in the Lomé Commune region to $+16.7 \%$ in the Centrale region(7). However, this study could not examine risk factors that could explain this heterogeneity of malaria prevalence in children under five in Togo. Several studies on malaria in Togo have focused on the clinical management of cases $(8,9)$, the evolution of malaria incidence (7), the evaluation of the implementation of malaria control interventions $(10,11)$, clinical trials on malaria vector resistance to insecticides $(29,30)$ and socio-cultural factors $(12)$. So far, there are very few studies examining the risk factors associated with regional heterogeneity in malaria prevalence among children under five in Togo using national population-based survey data (7). The aim of this study is to explore further regional heterogeneities in malaria prevalence and to determine the associated risk factors.

\section{Methods}

\section{Study context}

Togo is a country in West Africa, with an population of 7,886 million inhabitants for a density of 152 inhabitants/km2 in 2021 (13). It is bordered to the north by Burkina Faso, to the south by the Gulf of Guinea, to the east by Benin and to the west by Ghana. It has six health regions and forty-three health districts in total (Figure 1).

The health system in Togo is organized as a three-level pyramidal structure (3) (figure 2). The first level is composed of the central administration and the different departments and programs where the guidelines and national policies are developed. The regional (or intermediate) level includes six health regions which provide coordination and technical support to the third level health districts. The peripheral level is represented by the health district which is the most decentralized operational entity comprising of 43 health districts and 944 peripheral health units.

\section{Study Type And Sample Design}

This was a secondary data analysis project using cross-sectional data from the Togo Malaria Indicator Survey (TMIS) 2017. These data provide information on malaria prevalence among children under five and pregnancy women in the country(14). The TMIS carried out a two-stage sampling method to select 
the sample. Using information from the last general population census in Togo in 2010 (15), each region was subdivided into Enumeration Areas (EAs). Each area of study was separated into urban and rural parts to form the sampling strata. At the first level, 171 EAs were drawn with a probability proportional to the size of which 60 were urban and 111 rural. To have an update in the selected enumeration areas, a household enumeration was carried out, which provided a complete list of occupied households in each EA selected. At the second level, 30 households were drawn systematically in each EAs. All women aged 15-49 usually living in the selected households or present the night before the interview with or without children under five were eligible to be interviewed. Selected households with neither a woman aged 15-49 nor a child under five were only included for the household questionnaires. In total, the sample consisted of 171 EAs, 5,130 households (1,800 in urban areas and 3,330 in rural areas), 4,895 women from 15 to 49 years old (1,684 in urban areas and 3,211 in rural areas), and 3,271 children under five (2,441 in rural areas and 830 in urban areas)(16).

\section{Tools and data collection}

Three questionnaires were used in the context of the 2017 TMIS: a household questionnaire, a women questionnaire, and a biomarker questionnaire. The household questionnaire recorded all household members and visitors who slept there the night before the interviewer visited the household, water source, types of toilets, habitat characteristics, possession of durable goods, and use of mosquito nets were collected. The women questionnaire was used to collect information on socio-demographic characteristics, knowledge of malaria and prevention measures, births over the last 5 years, prevalence and treatment of fever in children under five. Finger prick blood samples for malaria testing were taken from all children aged 6-59 months in the selected households, for whom the parents or responsible adults had previously given their informed consent. Screening for malaria was done with a rapid diagnostic test (RDT), namely the SD Bioline Malaria Ag Pf/Pan with a sensitivity of $94.0 \%$ and specificity of $91.4 \%$. Children who tested positive for malaria, or who had other signs of severe malaria or other serious illnesses, were referred to the nearest health facility for "advice and action" following the national health policy in Togo. Blood collection on slides was carried out to confirm the infection status of all children using a microscope. After drying and fixing the blood smears, the prepared slides were stored in special boxes containing cold accumulators and humidity controllers. Blood samples on slides, accompanied by the transmission sheets, were regularly collected in the field and transported to the parasitology laboratory of the "Institut National d'Hygiene (INH)" to be registered, checked, and analysed. After being stained with Giemsa, the slides were examined for the presence of the parasite. Each slide was analysed independently and blindly by two different biologist technicians. In case of discrepancies between the results of the two technicians, the slide was re-examined by a senior biologist technician (16).

\section{Study Variables}


The dependent variable in this study is the infection status of the child (positive/negative) on the microscopic examination of the malaria parasitaemia. The main independent variable was the region. Other independent variables included environment related factors such as altitude, household density, main water source, type of toilet facility, main material of floors, main material of walls and main material of roof. Human related factors included household wealth quintiles, age, gender, possession and use of a mosquito bed net, mother's education level, knowing mosquitoes as vectors of malaria, being exposed to malaria prevention messages, as well as ethnicity and religion. We also took into account if the child had fever in last two weeks before the study. The household wealth quintile variable was constructed using principal component analysis on household's assets and amenities(17).

\section{Data analysis}

For each of the factors recorded, we assessed associations with malaria infection in univariate logistic regression using Generalized Linear Models (GLM), calculating odds ratios. Any association that was found to be statistically significant at a level of $p \leq 0.10$ in univariate analysis was assessed as a potential confounder in the association between region of residence and malaria infection. We then included in a multivariable model, region of residence and all the potential confounders as well as any other factors that were significantly associated in univariate analysis $(p \leq 0.10)$. We then removed one at a time, starting from the one with the highest $p$-value, each of the secondary exposures. If this resulted in a change of more than $10 \%$ in the odds ratio of region or if the likelihood ratio test comparing the complex model with the simple model was significant, the secondary exposure was retained. We then tried to remove the next secondary exposure, using the same criteria. This process was continued until all remaining secondary exposures were either important as confounders or their removal would result in a significantly less precise model(18). With the variables retained ( $p \leq 0.05$ or confounders), we checked for interactions between our main variable of interest (region of residence) and each of the secondary exposures. For this purpose, categorical variables with more than two levels were recoded to binary. Dose response curves were generated using the predictor effect plots (19) to show the trend between the malaria prevalence and certain associated risk factors. Data were analysed using the software $\mathrm{R}$ version 4.0.4.

[1] Sources of drinking water were recoded as improved (protected well, tube well or borehole, public tap/standpipe, protected spring) and unimproved (unprotected spring, unprotected well, rainwater, surface water, river/dam/stream/irrigation channel)

[2] Type of toilet facility were recoded as improved (pit toilet latrine, ventilated improved pit latrine, pit latrine with slab, flush toilet, flush to piped sewer system) and unimproved (no facility/bush/field, pit latrine without slab/open pit, bucket toilet)

[3] Main materials of floors were recoded as 'improved materials' (ceramic tiles, cement, vinyl asphalt strips, parquet and polished wood) and 'unimproved materials' (rudiments, wooden planks, earth, sand, palms, bamboo and others) 
${ }^{[4]}$ Main materials of wall were recoded as 'improved materials' (cement, stone with lime, cement blocks and bricks) or 'unimproved materials' (cane/palm/trunks, earth, bamboo or stone with mud, uncovered adobe, and others rudimentary materials)

[5] Main materials of roofs were categorised into "improved materials" (roofing shingles and cement) and "unimproved materials" (thatch, rudimentary, rustic matting, palm/bamboo, wooden planks, cardboard, and no roof)

\section{Results}

\section{Characteristics of the study population}

A total of 3,271 children aged between 0 and 59 months from 5,130 households were enrolled in the survey, of whom 2,867 aged 6-59 months were tested for the presence of malaria parasites. There were almost equal numbers of female and male children, with a median age of 27 months (IQR 13-43). Most children $(74.6 \%)$ were from rural areas, except for the Lomé Commune region, which is an urban agglomeration that includes the country's capital. The largest group of children in our sample $(28.7 \%)$ were from the poorest quintile of households, while only $12.4 \%$ were from the richest quintile (Table 1). Children living in the Plateaux region had the highest prevalence of malaria (43.6\%) followed by children living in the Savanes (31.9\%) and Maritime (29.5\%) regions. Intermediate prevalence levels of malaria were recorded in Kara (16.7\%) and Centrale (17.1\%), and the lowest prevalence level (5.3\%) in Lomé region (figure 1 and table 1). In addition, most of the children were living in houses where the main materials of the floor, wall and roof were not upgraded (table1)

\section{Regional heterogeneity of malaria in Togo}

The region of residence was significantly associated with the child's malaria status (Table 2). Part of the variability in malaria prevalence between regions was explained by the exposure variables explored, in particular: altitude, household density, main water source, type of toilet facility, main material of floors, main material of walls, main material of roof, household wealth quintiles, age, gender, possession and use of a mosquito bed net, mother's education level, knowing mosquitoes as vectors of malaria, being exposed to malaria prevention messages, ethnicity, religion, as well as child had fever in last two weeks before the study. The Plateaux and Maritime regions remained at increased risk compared to Lomé, while the other regions no longer had an increased risk. The probability of a positive malaria test with microscopy for children living in the Plateaux decreased from 13.7 times higher risk to 4.2 times higher risk compared to those living in the Lomé Commune region. In addition, the heterogeneity was no longer significant for three of the regions after adjusting for other risk factors (see table 2). The interaction tests performed during these analyses were not significant.

\section{Other associated risk factors with regional heterogeneity of malaria prevalence among children}


The table 2 summarised variables that had an independent statistically significant impact on the malaria prevalence. Children living in rural areas were at twice as high risk (adj. OR=2.02, 95\% $\mathrm{Cl}$ [1.32-3.13]) to test positive for malaria compared to those living in urban areas. Malaria prevalence was highest among children whose mother had no education (37.7\%), followed by those whose mother had primary education (27.2\%), and finally those whose mother had secondary education and above (14.3\%), showing a clear dose-response association as for each increase in the mother's education level, the probability of her child testing positive for malaria decreased. Regional heterogeneity of malaria prevalence in children under five was also in a dose-response manner associated with poorer wealth quintiles and older age of child proportion of children aged 36-59 months (Table 2). The statistical tests for child age, household wealth quintile, altitude and mother's educational level showed an dose-response trend. The probability of malaria in children decreased with the altitude, maternal educational level, and household wealth quintile. Also, this probability increased with child's age in months (figure 4).

\section{Discussion}

The prevalence of malaria in Togo in children under 5 years of age was high and varied by region, with the highest prevalence in the Plateaux region. After adjusting for several risk factors, the effect of region of residence decreased but remained significant. This suggests that the heterogeneity by region of residence may still reflect other important variables not considered in the study. Examples include temperature, humidity, the presence of standing water in the household, the proximity of the household to a body of water, availability and quality of health care. Children living in two of the six regions, Plateaux and Maritime, had a higher risk of contracting malaria. This finding could be partly explained by favourable climatic conditions in this region, especially high rainfall, which provides a breeding ground for the Anopheles mosquito, responsible for malaria transmission in these regions (20). Entomological studies in Nigeria (21) and Eritrea)(22), showed higher number of mosquitoes in the irrigated community compared to those in the non-irrigated community.

A higher risk of malaria in children living in rural areas may also be associated with more favourable conditions for mosquito development. Studies in Nigeria (23) and Burkina Faso (24) have shown that proximity of dwellings to agricultural areas and rural water reservoirs increases the risk of malaria morbidity due to greater exposure to malaria vectors. The difference in risk between rural and urban children was greater in the Lomé Commune region, the most urbanized region in Togo. Urbanization reduces the risk of malaria because it creates an environment which is suboptimal for mosquito persistence as it reduces the number of breeding sites $(25,26)$. Urbanization also changes health practices, which can result in more effective prevention (use of insecticides, mosquito nets, preventive treatments), information dissemination (concentration of public and private media), and better access to health facilities $(26,27)$. The difference in risk by region related to household wealth quintile may suggest that malaria prevalence in children has a strong association with household wealth quantile $(28,29)$. In contrast to this result, similar studies in Uganda (30) and Kenya (25), did not find an association between household wealth index and malaria prevalence. However, the difference with these results could be explained by the fact that these two studies were conducted in single rural communities. Therefore, these 
may not be generalisable nor comparable to national survey data that includes both urban and rural populations and a mix of different communities.

The higher malaria prevalence in older age groups observed in our study is consistent with observations in Kenya (31) and Tanzania (32). An explanation could be that younger children have anti-malaria antibodies that have been transmitted to them by their mothers $(32,33)$. Or that they spent less time outdoors in the evenings compared to older children, resulting in less exposure and are likely to be put under bed nets regularly (23). Other explanations may include the fact that they have received Seasonal Malaria Chemo-prevention (SMC). This could guide considerations of more targeted malaria control strategies for older children, such as extending the age group covered by SMC.

Children living in areas with high malaria transmission intensity develop immunity with age because of continuous exposure to infected mosquito bites (34). This immunity develops first against severe forms of malaria and then against non-severe malaria. This could explain that older children are more likely to have malaria parasites without developing clinical disease, in contrast to their younger counterparts who still have immature immunity and therefore still struggling with malaria infections (33).

The mother's educational level showed a protective effect against malaria infection for her child. The same results were found using cross-sectional survey data from three African countries (Angola, Tanzania, Uganda) (35) and also in Democratic Republic of Congo (36). An educated mother has a higher capacity for self-reliance and can break with certain traditions and beliefs that are not favourable to health. She can also make arrangements to keep the household healthy and improve hygiene (37). This effect of a mother's education on child survival is true even in poor households $(38,39)$. Indeed, educated mothers are more receptive to awareness campaigns to prevent their children from getting sick, and are quick to consult and use health services (39).

The dataset used for the analyses was derived from a cross-sectional survey and therefore has some limitations. For example, a causal relationship between the explanatory variables and the prevalence of malaria in children under five cannot be established. Data were also collected on adherence to the first dose of seasonal malaria chemoprevention (SMC) drug in 2017. SMC was only available in three regions and 1,061 children were exposed to the treatment as reported by caregivers with $99.9 \%$ adherence during the survey. Because of this low number of children exposed to SMC in the study sample, we were unable to control for this variable in the analyses.

The large and nationally representative study population is an important strength of the study. Another strength of the study is that the malaria infection was diagnosed by microscopy, which is the gold standard. In addition, the use of Generalized Linear Models allowed explaining part of the regional heterogeneity of malaria prevalence in under-five in Togo and the associated risk factors. This information can thus be essential in the design of appropriate interventions.

\section{Conclusion}


The results obtained in this study show a strong regional heterogeneity of malaria prevalence in children under five years of age in Togo. Part of this heterogeneity could be related to factors such as place of residence, child's age, mother's education level, household wealth quintile, exposure to malaria prevention messages and altitude, but after adjusting for these, significant heterogeneity persisted. These findings support designing targeted interventions and strategies tailored to older children living in rural areas and from households with a poor wealth index. Particular emphasis could be placed on designing key malaria prevention messages for the high malaria prevalence regions. Prioritising high prevalence regions for SMC and the combined use of preventive measures is recommended for better control of malaria in Togo.

\section{Abbreviations}

CHW: Community Health Workers, CBRS: “Comité Bioéthique de Recherche en Santé, DALY : DisabilityAdjusted Life Years, EA: Enumeration Areas, GLM: Generalized Linear Models, INSEED: National Institute of Statistics, IRS : Indoor Residual Spraying, LLIN: Long-lasting Insecticidal Nets, PNLP: National Malaria Control Program, RDT: Rapid Diagnostic Test, SMC: Seasonal Malaria Chemo-prevention, TMIS: Togo Malaria Indicator Survey, WHO: World Health Organization.

\section{Declarations}

\section{Acknowledgements}

Thanks to the ICF International and DHS (Demographic and Health Surveys) Program for providing and granting permission for the use of the data in this study and to the Ministry of health, public hygiene and universal access to care, Togo for their support and advise. Our special thanks are owed to DGD finding, Institute of Tropical Medicine, Antwerp MPH staff and jury. Thanks to Prof. Epco Hasker for his advice on data analysis.

\section{Authors' contributions :}

KG and MS designed the study. SS, GK and MS performed the data analysis. WG, AAK and DKE drafted the manuscript. All co-authors contributed significantly to the revision of the manuscript and provided scientific guidance. All authors read and approved the final manuscript

\section{Ethics approval and consent to participate}

The ethical approval for the study protocol was obtained from the ICF International's Institutional Review Board and the Togo Bioethics Committee for Health Research (CBRS). Moreover, informed consent was obtained from study participants prior data collection. For this study, Dataset and permission to conduct secondary data analysis were granted by the DHS program. The data that were used in this analysis were anonymous and no personal identifier or link was received from the DHS program.

\section{Consent for publication}


Not applicable.

\section{Funding}

No funding was available for this study.

\section{Competing interests}

The authors declare that they have no competing interests.

\section{Availability of data and materials:}

DHS datasets are publicly available on www.dhsprogram.org.

\section{References}

1. World Health Organization. Fact sheet about Malaria [Internet]. 2019 [cited 2021 Jan 20]. Available from: https://www.who.int/news-room/fact-sheets/detail/malaria

2. Protopopoff N, Bortel WV, Speybroeck N, Geertruyden J-PV, Baza D, D'Alessandro U, et al. Ranking Malaria Risk Factors to Guide Malaria Control Efforts in African Highlands. PLOS ONE. 2009 Nov 25;4(11):e8022.

3. Ministry of Health/Togo. Annual performance report 2018 [Internet]. [cited 2021 Jan 9]. Available from: https://www.afro.who.int/sites/default/files/201909/RAPPORT\%20ANNUEL\%20DE\%20PERFORMANCE\%202018\%20DU\%20MSHP.pdf

4. Sanoussi Y, Ametoglo M. Ampleur Et déterminants des dépenses catastrophiques de santé: cas des ménages togolais (Magnitude and Determinants of Catastrophic Health Expenditure: Case of Togolese Households) [Internet]. Rochester, NY: Social Science Research Network; 2019 Aug [cited 2021 Jan 23]. Report No.: ID 3440106. Available from: https://papers.ssrn.com/abstract=3440106

5. World Health Organization. Global technical strategy for malaria, 2016-2030 [Internet]. Geneva; 2015 [cited 2020 Dec 28]. Available from: http://apps.who.int/iris/bitstream/10665/176712/1/9789241564991_eng.pdf?ua=1

6. Ministry of health/Togo. National Health Development Plan (PNDS) 2017-2022 [Internet]. [cited 2021 Jan 9]. Available from: https://sante.gouv.tg/node/359

7. Bakai TA, Thomas A, Iwaz J, Atcha-Oubou T, Tchadjobo T, Khanafer N, et al. Changes in registered malaria cases and deaths in Togo from 2008 to 2017. International Journal of Infectious Diseases. 2020 Dec;101:298-305.

8. Gbadoé AD, Kini-Caussi M, Koffi S, Traoré H, Atakouma DY, Tatagan-Agbi K, et al. Évolution du paludisme grave de l'enfant au Togo de 2000 à 2002. Médecine et Maladies Infectieuses. 2006 Jan 1;36(1):52-4.

9. Déti EK, Flénon J, Zohoun T, Maurice-Tison S, Salamon R, Atakouma YD. Prise en charge à domicile du paludisme chez l'enfant: propositions d'actions à partir des résultats d'une enquête CAP menée 
auprès des mères d'enfants de moins de 5 ans à Notsé (Togo). Cahiers d'études et de recherches francophones / Santé. 2008 Mar 1;18(3):155-61.

10. Thomas A, Bakai TA, Atcha-Oubou T, Tchadjobo T, Voirin N. Implementation of a malaria sentinel surveillance system in Togo: a pilot study. Malar J. 2020 Dec;19(1):330.

11. Wang Q, Zhang Z, Yu W, Lu C, Li G, Pan Z, et al. Surveillance of the Efficacy of ArtemisininPiperaquine in the Treatment of Uncomplicated Plasmodium falciparum Malaria Among Children Under 5 Years of Age in Est-Mono District, Togo, in 2017. Front Pharmacol. 2020;11:784.

12. Kpanake L, Dassa KS, Mullet E. Why most Togolese people do not seek care for malaria in health care facilities: a theory-driven inventory of reasons. Psychol Health Med. 2009 Aug;14(4):502-10.

13. National Institute of Statistics (INSEED). Socio-Demographic Indicators [Internet]. 2021 [cited 2021 Oct 24]. Available from: https://inseed.tg/

14. The DHS Program - Togo: Malaria Indicator Survey (MIS), 2017 [Internet]. [cited 2020 Dec 29]. Available from: https://dhsprogram.com/methodology/survey/survey-display-497.cfm

15. National Institute of Statistics (INSEED). General Census of Population and Housing_Togo 2010 [Internet]. Togo: INSEED; 2011 Dec [cited 2020 Dec 29] p. 65. Available from: https://inseed.tg/statistiques-demographiques/

16. Ministry of Health, ICF. Togo Malaria Indicator Survey 2017 [Internet]. 2018 Feb [cited 2021 Jun 13] p. 165. Available from: https://dhsprogram.com/publications/publication-MIS29-MIS-FinalReports.cfm

17. Krefis AC, Schwarz NG, Nkrumah B, Acquah S, Loag W, Sarpong N, et al. Principal component analysis of socioeconomic factors and their association with malaria in children from the Ashanti Region, Ghana. Malaria Journal. 2010 Jul 13;9(1):201.

18. Tingley D, Yamamoto T, Hirose K, Keele L, Imai K. mediation: R package for causal mediation analysis. UCLA Statistics/American Statistical Association [Internet]. 2014 Aug [cited 2021 Nov 14]; Available from: https://dspace.mit.edu/handle/1721.1/91154

19. Fox J, Weisberg S. Visualizing Fit and Lack of Fit in Complex Regression Models with Predictor Effect Plots and Partial Residuals. Journal of Statistical Software. 2018 Nov 30;87:1-27.

20. Pierre C, Vincent R. Les anophèles: Biologie, transmission du Plasmodium et lutte antivectorielle. IRD Éditions; 2017. 404 p.

21. Amaechi EC, Ukpai OM, Ohaeri CC, Ejike UB, Irole-Eze OP, Egwu O, et al. Distribution and seasonal abundance of Anopheline mosquitoes and their association with rainfall around irrigation and nonirrigation areas in Nigeria. Cuadernos de Investigación UNED. 2018 Dec;10(2):267-72.

22. Kifle MM, Teklemariam TT, Teweldeberhan AM, Tesfamariam EH, Andegiorgish AK, Azaria Kidane E. Malaria Risk Stratification and Modeling the Effect of Rainfall on Malaria Incidence in Eritrea. Journal of Environmental and Public Health. 2019 Apr 1;2019:1-11.

23. Oguoma VM, Anyasodor AE, Adeleye AO, Eneanya OA, Mbanefo EC. Multilevel modelling of the risk of malaria among children aged under five years in Nigeria. Trans R Soc Trop Med Hyg. 2020 Sep 18; 
24. Ouédraogo M, Samadoulougou S, Rouamba T, Hien H, Sawadogo JEM, Tinto H, et al. Spatial distribution and determinants of asymptomatic malaria risk among children under 5 years in 24 districts in Burkina Faso. Malar J. 2018 Dec 7;17(1):460.

25. Snow RW, Peshu N, Forster D, Bomu G, Mitsanze E, Ngumbao E, et al. Environmental and entomological risk factors for the development of clinical malaria among children on the Kenyan coast. Trans R Soc Trop Med Hyg. 1998 Aug;92(4):381-5.

26. Gazin P. Le paludisme en Afrique au sud du Sahara: comparaison entre les milieux urbains et ruraux. Cahiers d'études et de recherches francophones / Santé. 1991 Apr 1;1(1):33-8.

27. Bouba Djourdebbé $F$. Facteurs environnementaux immédiats et santé des enfants dans les zones de l'Observatoire de population de Ouagadougou (Burkina Faso). 2016 Mar 23 [cited 2021 Jan 22]; Available from: https://papyrus.bib.umontreal.ca/xmlui/handle/1866/13592

28. Kanmiki EW, Awoonor-Williams JK, Phillips JF, Kachur SP, Achana SF, Akazili J, et al. Socio-economic and demographic disparities in ownership and use of insecticide-treated bed nets for preventing malaria among rural reproductive-aged women in northern Ghana. PLoS One [Internet]. 2019 Jan 29 [cited 2021 Jan 18];14(1). Available from: https://www.ncbi.nlm.nih.gov/pmc/articles/PMC6350974/

29. Uzochukwu BS, Onwujekwe OE. Socio-economic differences and health seeking behaviour for the diagnosis and treatment of malaria: a case study of four local government areas operating the Bamako initiative programme in south-east Nigeria. Int J Equity Health. 2004 Jun 17;3(1):6.

30. Pullan RL, Bukirwa H, Staedke SG, Snow RW, Brooker S. Plasmodium infection and its risk factors in eastern Uganda. Malar J. 2010 Jan 4;9:2.

31. Bashir IM, Nyakoe N, van der Sande M. Targeting remaining pockets of malaria transmission in Kenya to hasten progress towards national elimination goals: an assessment of prevalence and risk factors in children from the Lake endemic region. Malar J. 2019 Dec;18(1):233.

32. Roberts $D$, Matthews $G$. Risk factors of malaria in children under the age of five years old in Uganda. Malar J. 2016 Apr 27;15:246.

33. Carnevale $P$, Vaugelade J, Programme WHOMA. Paludismes, morbidité palustre et mortalité infantile et juvénile en Afrique sub-saharienne. 1987 [cited 2020 Dec 29]; Available from: https://apps.who.int/iris/handle/10665/59447

34. Musa MI, Shohaimi S, Hashim NR, Krishnarajah I. A climate distribution model of malaria transmission in Sudan. Geospatial health. 2012 Nov;7(1):27-36.

35. Njau JD, Stephenson R, Menon MP, Kachur SP, McFarland DA. Investigating the Important Correlates of Maternal Education and Childhood Malaria Infections. Am J Trop Med Hyg. 2014 Sep 3;91(3):509-19.

36. Ma C, Claude KM, Kibendelwa ZT, Brooks H, Zheng X, Hawkes M. Is maternal education a social vaccine for childhood malaria infection? A cross-sectional study from war-torn Democratic Republic of Congo. Pathogens and Global Health. 2017 Feb 17;111(2):98-106.

37. Mattos T, Mackinnon MA, Boorse D. The Intersection of Gender, Education, and Health : A Community-level Survey of Education and Health Outcomes for Women in Southeastern Togo 
[Internet]. 2012 [cited 2020 Dec 29]. Available from: / paper/The-Intersection-of-Gender-\%2CEducation-\%2C-and-Health-Mattos-Mackinnon/a776c16b09a17705b70fd4749afecdea109892d0

38. Peña R, Wall S, Persson LA. The effect of poverty, social inequity, and maternal education on infant mortality in Nicaragua, 1988-1993. Am J Public Health. 2000 Jan;90(1):64-9.

39. Caldwell J, McDonald P. Influence of maternal education on infant and child mortality: levels and causes. Health Policy Educ. 1982 Mar;2(3-4):251-67.

\section{Tables}

Table 1: Characteristics of the study population 


\begin{tabular}{|c|c|}
\hline Factor & Number (\%) \\
\hline \multicolumn{2}{|l|}{ Health Region } \\
\hline Lomé Commune & $462(14.1)$ \\
\hline Maritime & $545(16.7)$ \\
\hline Plateaux & $582(17.8)$ \\
\hline Centrale & $468(14.3)$ \\
\hline Kara & $510(15.6)$ \\
\hline Savanes & $704(21.5)$ \\
\hline \multicolumn{2}{|l|}{ Place of residence } \\
\hline Rural & $2441(74.6)$ \\
\hline Urban & $830(25.4)$ \\
\hline \multicolumn{2}{|l|}{ Gender } \\
\hline Male & 1635 (49.9) \\
\hline Female & $1636(50.1)$ \\
\hline \multicolumn{2}{|l|}{ Age in months } \\
\hline $06-23$ & $1075(32.8)$ \\
\hline $24-35$ & $615(18.9)$ \\
\hline $36-59$ & $1581(48.3)$ \\
\hline \multicolumn{2}{|c|}{ Had fever in last two weeks } \\
\hline No & $2442(74.7)$ \\
\hline Yes & $829(25.3)$ \\
\hline \multicolumn{2}{|c|}{ Child slept under bednet } \\
\hline No one & $748(22.9)$ \\
\hline Some & $279(8.5)$ \\
\hline All & $2244(68.6)$ \\
\hline \multicolumn{2}{|l|}{ Mother's ethnicity } \\
\hline Kabye_tem & $965(29.5)$ \\
\hline Mina & $1096(33.5)$ \\
\hline Para-gourma & $896(27.4)$ \\
\hline
\end{tabular}




\begin{tabular}{lr} 
Stranger & $119(03.7)$ \\
\hline Other & $195(05.9)$ \\
\hline Mother's religion & $1036(31.6)$ \\
\hline Animist & $1664(50.9)$ \\
\hline Christian & $566(17.3)$ \\
\hline Muslim & $05(00.2)$ \\
\hline Other & $1432(43.8)$ \\
\hline Mother's educational level & $1051(32.1)$ \\
\hline No education & $788(24.1)$ \\
\hline Primary & \\
\hline Secondary or higher & $753(23.0)$ \\
\hline Mother's age in years & $1744(53.3)$ \\
\hline $15-24$ & $774(23.7)$ \\
\hline $25-34$ &
\end{tabular}


Exposed to malaria messages

\begin{tabular}{|c|c|}
\hline No & $2492(76.2)$ \\
\hline Yes & $779(23.8)$ \\
\hline \multicolumn{2}{|c|}{ Knowing mosquitoes as vectors of malaria } \\
\hline No & 585 (17.9) \\
\hline Yes & $2686(82.1)$ \\
\hline \multicolumn{2}{|c|}{ Have mosquito bed net for sleeping } \\
\hline No & $174(05.3)$ \\
\hline Yes & $3097(94.7)$ \\
\hline \multicolumn{2}{|c|}{ Socio economic status } \\
\hline Poorest & $940(28.7)$ \\
\hline Poorer & $794(24.3)$ \\
\hline Middle & $617(18.9)$ \\
\hline Richer & $513(15.7)$ \\
\hline Richest & $407(12.4)$ \\
\hline \multicolumn{2}{|c|}{ Main floor material } \\
\hline Improved & $2665(81.5)$ \\
\hline Unimproved & $606(18.5)$ \\
\hline \multicolumn{2}{|c|}{ Main wall material } \\
\hline Improved & $1958(59.8)$ \\
\hline Unimproved & $1313(40.2)$ \\
\hline \multicolumn{2}{|c|}{ Main roof material } \\
\hline Improved & $2734(83.6)$ \\
\hline Unimproved & $537(16.4)$ \\
\hline \multicolumn{2}{|c|}{ Main water source } \\
\hline Improved & $2026(61.9)$ \\
\hline Unimproved & $1245(38.1)$ \\
\hline \multicolumn{2}{|c|}{ Type of toilets facility } \\
\hline Improved & 1166 (35.6) \\
\hline
\end{tabular}


Unimproved

Density in the household

1-2 persons

3-4 persons

$5+$ persons

Altitude in metres

0-300

301-600

601 and more
$2105(64.4)$

$33(01.0)$

758 (23.2)

$2480(75.8)$
$2479(75.8)$

749 (22.9)

43 (01.3)

Table2: Regional heterogeneity of malaria and associated risk factors among children in Togo in 2017 
Factors

Positive malaria* $(n=829)$

Number (\%)

Health region

Lomé

Commune

Maritime

$161(29.5)$

Plateaux

$254(43.6)$

Centrale

$87(17.1)$

Kara

77 (16.7)

225 (31.9)

Savanes

66 (8.0)

763 (31.2)

Place of

residence

Urban

Rural
Negative malaria* (2442)

Number (\%)
OR $(95 \%$

$\mathrm{Cl})$ aOR $(95 \%$

$\mathrm{Cl})$ 
Exposed to malaria messages

$\begin{array}{lllll}\text { No } & 694(27.8) & 1798(72.2) & \text { Ref. } & \text { Ref. } \\ \text { Yes } & 135(17.3) & 644(82.7) & 0.56 & 0.67 \\ & & & (0.45-0.69) & (0.53- \\ & & & 0.85)\end{array}$

Household wealth quintile

\begin{tabular}{lllll}
\hline Poorest & $351(37.3)$ & $589(62.7)$ & Ref. & Ref. \\
\hline Poorer & $241(30.3)$ & $645(69.7)$ & $0.52(0.41-$ & 0.85 \\
& & & $0.66)$ & $\begin{array}{l}(0.67- \\
1.07)\end{array}$ \\
\hline Middle & $149(24.1)$ & $376(75.9)$ & $0.42(0.38-$ & 0.61 \\
& & & $0.58)$ & $(0.45-$ \\
Richer & $72(14.0)$ & $441(86.0)$ & & $0.80)$ \\
& & & $0.37)$ & 0.64 \\
& & & & $0.42-$ \\
Richest & $16(4.0)$ & $391(96.0)$ & $0.07(0.04-$ & 0.22 \\
& & & $0.11)$ & $0.11-$ \\
& & & & $0.41)$
\end{tabular}

Altitude in metres

\begin{tabular}{lccll}
\hline $0-300$ & $715(29.0)$ & $1764(71.0)$ & Ref. & Ref. \\
\hline $301-600$ & $108(14.4)$ & $641(85.6)$ & $0.41(0.32-$ & 0.45 \\
& & & $0.51)$ & $0.33-$ \\
& & & & $0.60)$ \\
\hline $\begin{array}{l}601 \text { and } \\
\text { more }\end{array}$ & $6(14.0)$ & $37(86.0)$ & $0.37(0.14-$ & 0.23 \\
& & & $0.83)$ & $0.08-$ \\
& & & & $0.55)$
\end{tabular}

OR: Crude OR, aOR : Adjusted odds ratio for all other factors considered in the multivariate analysis., Ref: reference modality, * Results of the malaria test performed under the microscopy

Figures 


\section{TOGO}

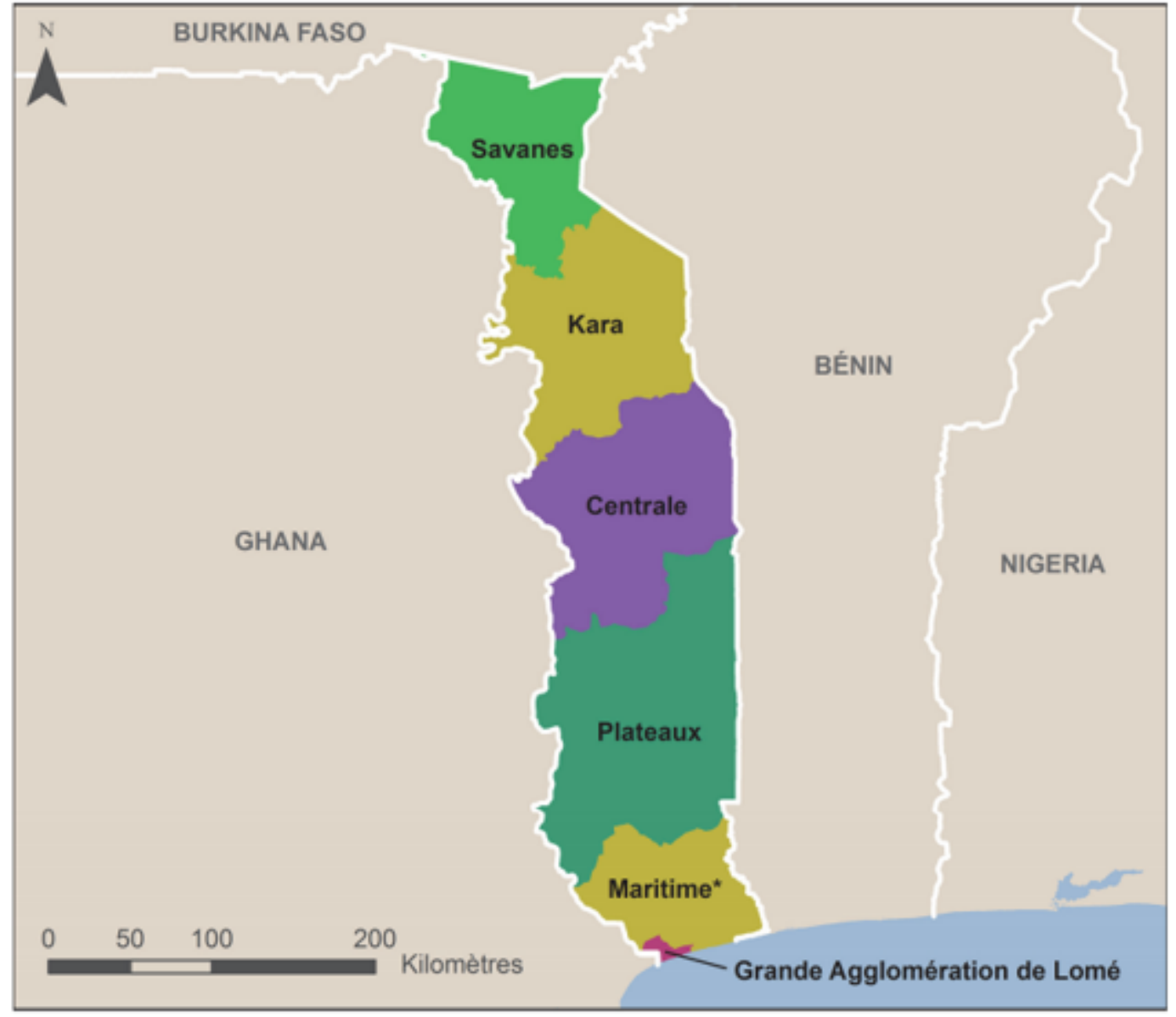

\section{Figure 1}

Togo administrative map (Ministry of Health 2017) 


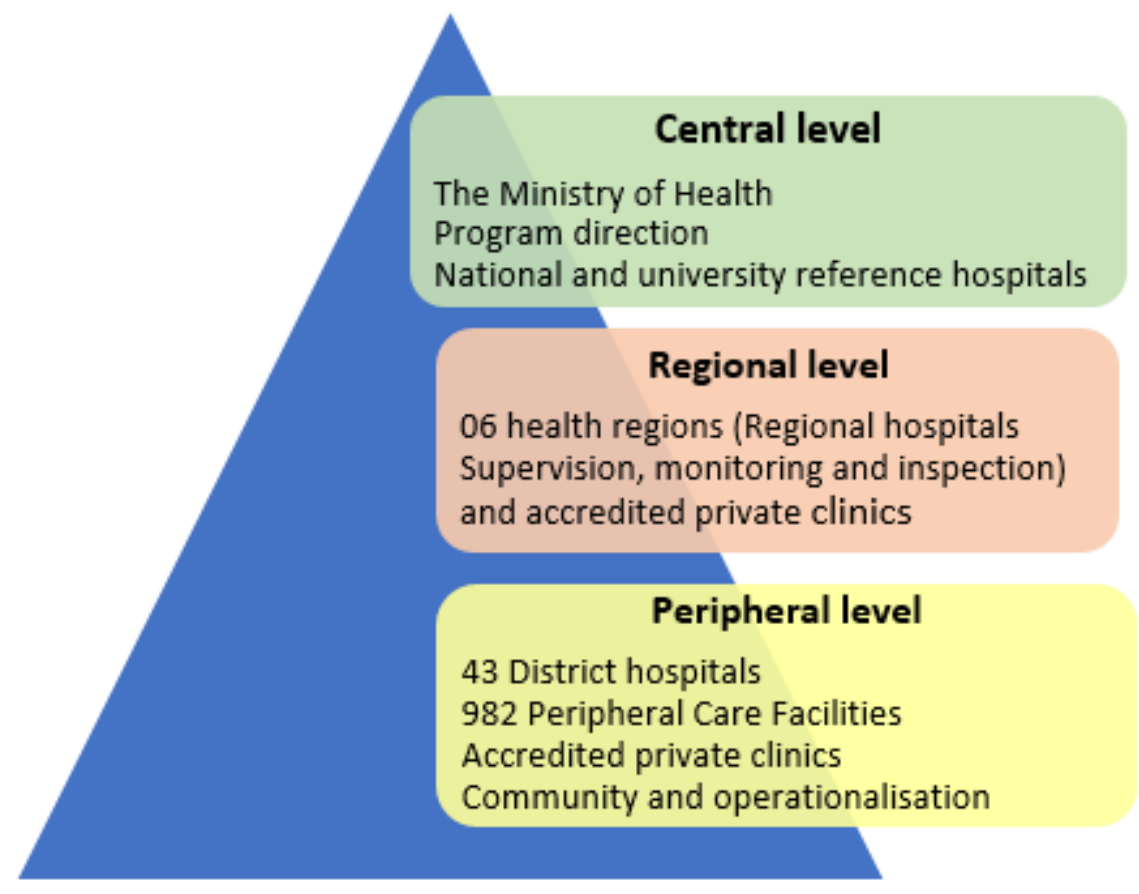

Figure 2

Togo's health system pyramid (Ministry of health, 2017)

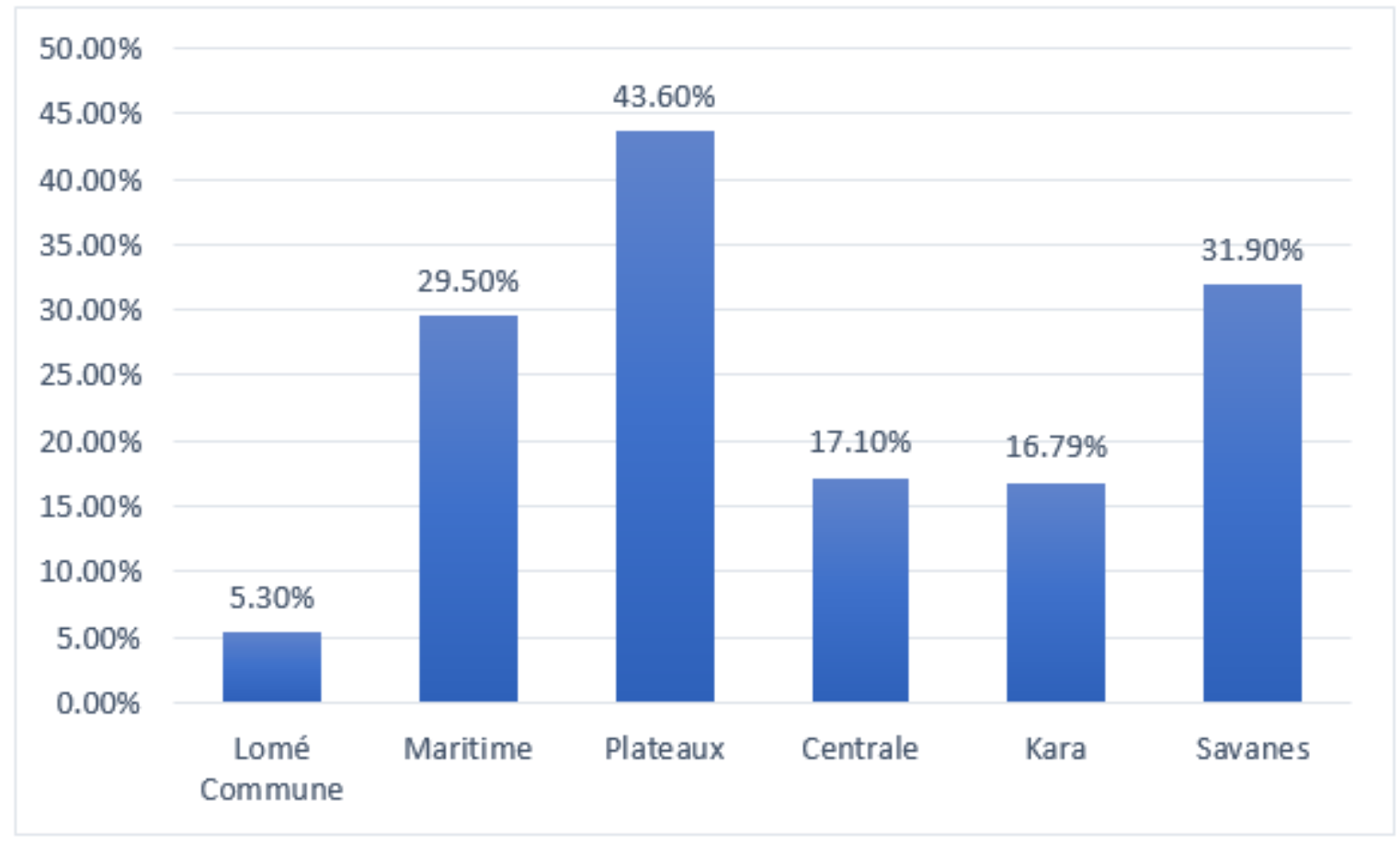

\section{Figure 3}

Malaria prevalence in children by region in Togo in 2017 

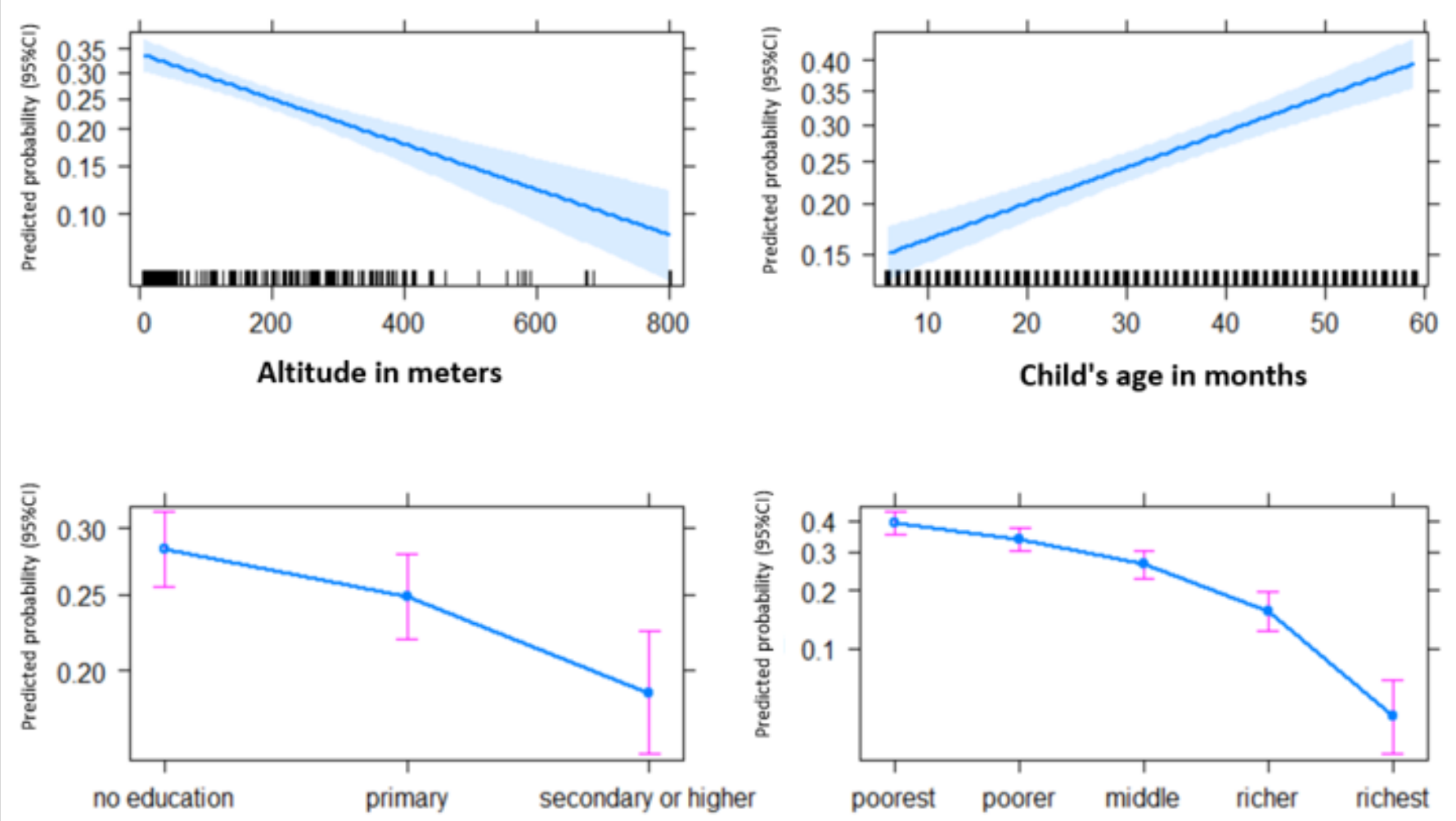

Mother's educational level

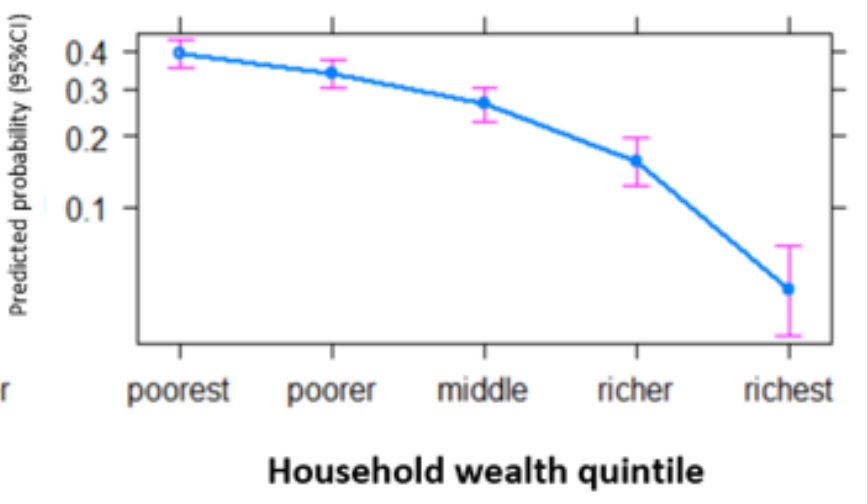

Figure 4

Predicted probabilities of malaria on altitude, child age, mother educational level and household wealth quintile. 